\title{
Factors influencing South African optometry stu- dents in choosing their career and institution of
} learning

\author{
KP Mashige ${ }^{\dagger}$ and OA Oduntan
}

†Discipline of Optometry, School of Physiotherapy, Sport Science and Optometry, Faculty of Health Sciences, University of KwaZulu-Natal, Westville Campus, Private Bag X54001, Durban, 4000 South Africa

†<mashigek@ukzn.ac.za>

‡<oduntanoa@ukzn.ac.za>

Received 21 December 2010; revised version accepted 24 February 2011

\begin{abstract}
The choice of an appropriate career, occupation or profession is one of the most important decisions that one makes in life and there are many factors which may influence such a decision. The purpose of this study was to establish the factors which influenced students currently studying optometry in South African institutions in deciding on the course of study and choice of institution. Data was collected with a questionnaire on demographics of the students and the factors that might have influenced their choice of optometry as a career and their institution of learning. Data was analysed with descriptive and cross-tabulation statistics. Three hundred and eighty seven students responded to the questionnaire ( $80.1 \%$ response rate). Their ages ranged from 17 to 40 years with a mean of $20.73 \pm 2.46$ years and included $30.5 \%$ males and $69.5 \%$ females. They were from the University of Free State (25.1\%), University of Johannesburg (29.5\%), University of KwaZulu-Natal (29.7\%) and the Univer-
\end{abstract}

\section{Introduction}

Choice of career is a result of a lifelong process that starts long before school leaving age ${ }^{1}$. Career aspirations expressed by adolescents are mostly un- sity of Limpopo (15.7\%). There were 38\% Whites, $36.7 \%$ Blacks, $22.2 \%$ Indians and 3.1\% Coloureds. The highest rated factors which influenced their choice of optometry were the desire to help other people $(92.8 \%)$, job availability after graduation (92\%), subjects passed and points obtained in the matric year $(91.2 \%)$ and the potential to earn a good salary (88.6\%), respectively. Few rated news and other media $(20.9 \%)$ as an important factor in their decision to choose their current institution of learning while $29.5 \%$ reported that failure to gain admission to study other degrees was an important factor. These results may be useful to institutions offering optometry degrees to formulate effective recruitment strategies to attract quality students. Also, they may be useful to career counsellors in counselling prospective students on their career choice and institution of learning. (S Afr Optom 2011 70(1) 21-28)

Key words: Optometry, South African optometry students, tertiary education, careers, South African universities

stable and tend to change many times before adulthood $^{2}$. The changes occur due to social issues, family background, economic status, access to opportunity structures and individual characteristics ${ }^{1,2}$. A wrong choice of career may result in anxiety with negative 
impact ${ }^{3}$. Undesirable situations such as poor financial remuneration may prompt some people to leave one profession to pursue other options that may be more financially rewarding 4 . There are many factors which may influence the choice of a career; and these include personal interest, prospects of good financial remuneration and family influence, where a parent or family member recommends the career ${ }^{5-9}$. Other factors include enthusiasm, challenge, motivation to help others and the ability to define one's own personal goals ${ }^{10}$. For example, studies involving ophthalmology residents in choosing ophthalmology revealed intellectual stimulation, the desire to acquire skills, perceived prestige and attractive working hours and conditions ${ }^{11-13}$. Several studies ${ }^{5,}$ 6, 14-16 involving health sciences students in South Africa and other parts of the world highlight income, job accessibility, a desire to help others and previous knowledge of the profession as some of the major reasons for choosing specific careers.

There are four institutions in South Africa currently offering the professional four-year Bachelor of Optometry degree (BOptom). They are the universities of Free State (UFS), Johannesburg (UJ), KwaZulu-Natal (UKZN) and the University of Limpopo (UL). Existing reports ${ }^{17}$ suggests that optometry departments do not face difficulties regarding the number of students that they wish to admit. However, they have to compete with other institutions for the students with high matriculation scores. Also, there is no guarantee that there will be no difficulties in the future in recruiting students with high matric points to study optometry. Further, reports ${ }^{17,18}$ suggest that there are racial and gender imbalances in the number of students admitted into each institution offering optometry. Female students constituted the majority $(72.7 \%)$ of the 2006 graduates from the four institutions ${ }^{18}$.

We did not find any studies that assessed factors affecting the choice of optometry as a career or the institution of learning in South Africa. Obviously, such studies are important as there would be factors that influence students, registering for the course in the country, and such information would be useful to the institutions offering the programme. Thus a survey among all students studying optometry was carried out between March and June 2010 to establish factors that they considered influenced their choice of optometry as a career and of their institutions of learning. As various institutions wish to recruit qual- ity prospective students, active steps should be taken to identify the variable factors that influence the decisions of students. This paper provides some insights into some of these factors.

\section{Methodology}

Approval to conduct this study was obtained from the University of KwaZulu-Natal's Research and Ethics Committee (Reference number: FECHSC 071/9). A questionnaire (Appendix 1) on the demography of the students and factors that might have influenced their choice of career and institution of learning was used for data collection. The design of the questionnaire was based on the review of relevant literature ${ }^{3}$, 4, 7-16. The survey was preceded by a pilot study conducted among twenty optometry students who did not take part in the final study in order to critically evaluate and finalise the questionnaire. All queries from the questionnaire during the pilot study were addressed and the questionnaire adjusted accordingly before the final study was conducted. Following permission from the heads of the various departments to conduct the survey, copies of the questionnaire were distributed by a staff member in each institution to optometry students in their first to fourth years who agreed to participate in the study. Participants were informed of the purpose of the study and that their participation in the study was voluntary. Those who agreed to partake in the study signed consent forms and were assured of the confidentiality of information provided. Data was analysed with the Statistical Programme for Social Sciences (SPSS), version 15.0.

\section{Results}

The total number of registered and eligible students in 2010 for the research within the optometry programmes was four hundred and eighty. Four hundred and eighty $(N=480)$ questionnaires were distributed to students and 387 students completed the questionnaires giving a response rate of $80.1 \%$. The majority of the students (97\%) were South Africans and were from the KwaZulu-Natal province (29.2\%), Gauteng (21.2\%), Free State (13.2\%), Limpopo (11.1\%), Mpumalanga (4.7\%), North West $(2.1 \%)$, Eastern Cape (7.2\%), Northern Cape (2.6\%) and Western Cape $(5.7 \%)$. Others (3\%) were international students from Namibia (1\%), Zimbabwe (0.5\%), Swaziland (0.5\%), 
Botswana $(0.4 \%)$, Mauritius $(0.3 \%)$ and Sweden $(0.3 \%)$. They were from urban $(72.6 \%)$ and rural areas $(27.4 \%)$. Respondents were from the Departments of Optometry of UFS (25.1\%), UJ (29.5\%), UKZN $(29.7 \%)$ and UL $(15.7 \%)$ and were in the first year $(23.8 \%)$, second year $(23.5 \%)$, third year $(25.9 \%)$, and fourth year $(26.8 \%)$. Their ages ranged from 17 to 40 years with a mean of $20.73 \pm 2.46$ years. They included $30.5 \%$ male and $69.5 \%$ female and were $38 \%$ Whites, $36.7 \%$ Blacks, $22.2 \%$ Indians and 3.1\%

\section{Coloureds.}

Optometry was the first choice of $60.5 \%$ of the respondents, while $29.5 \%$ indicated that they were studying optometry because they were not admitted for their first choice of study. The altruistic factor of helping other people was the most commonly cited factor that influenced their career choice (see Figure 1). For many, $(76.5 \%)$ their current institutions were their institutions of first choice (see Figure 2).

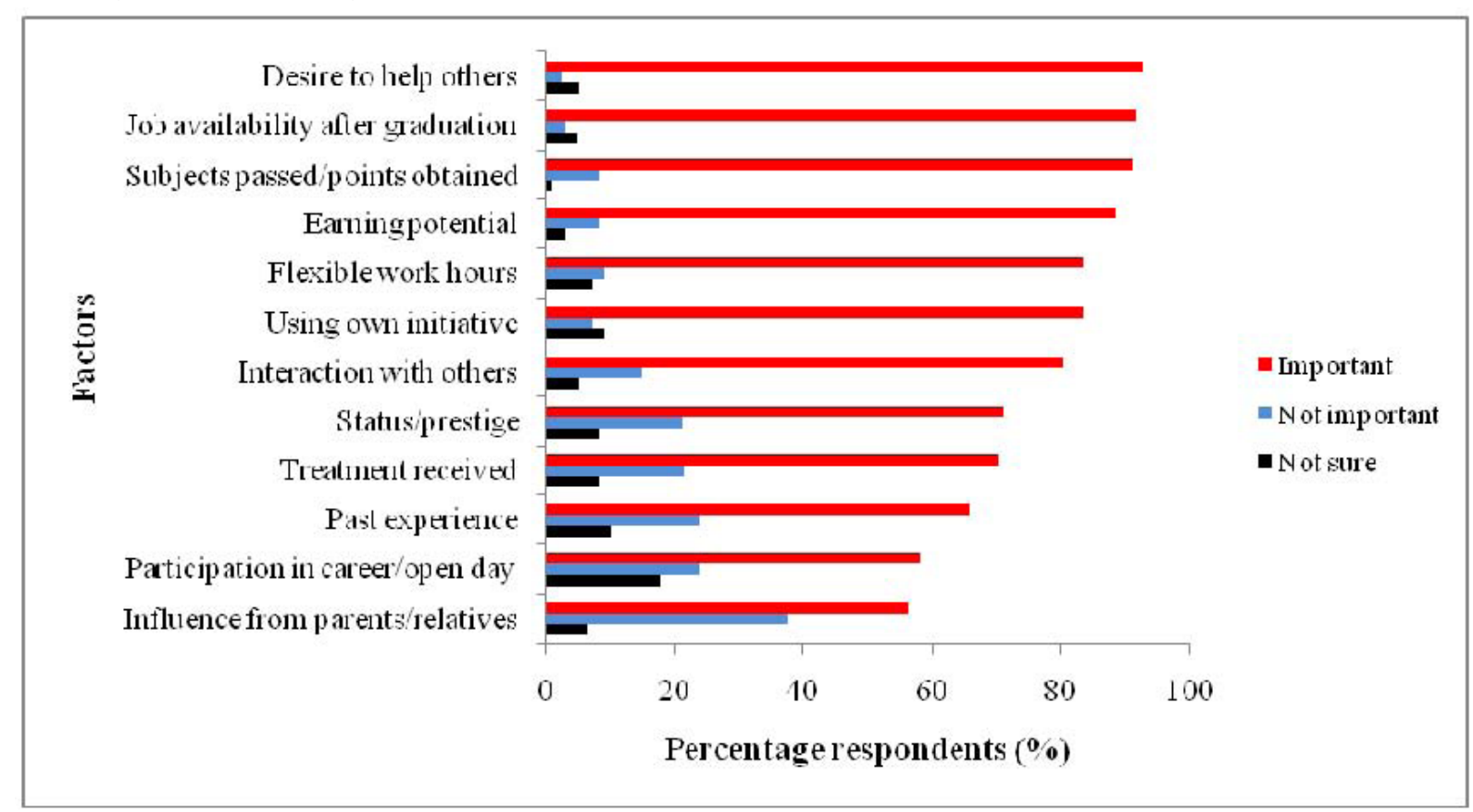

Figure 1: The ranking of importance of factors which influenced the decision of the respondents to pursue optometry as a career. Most of the students ( $90 \%$ and above) rated the desire to help others, job availability and subjects passed and points earned as important factors for deciding on optometry as a career.

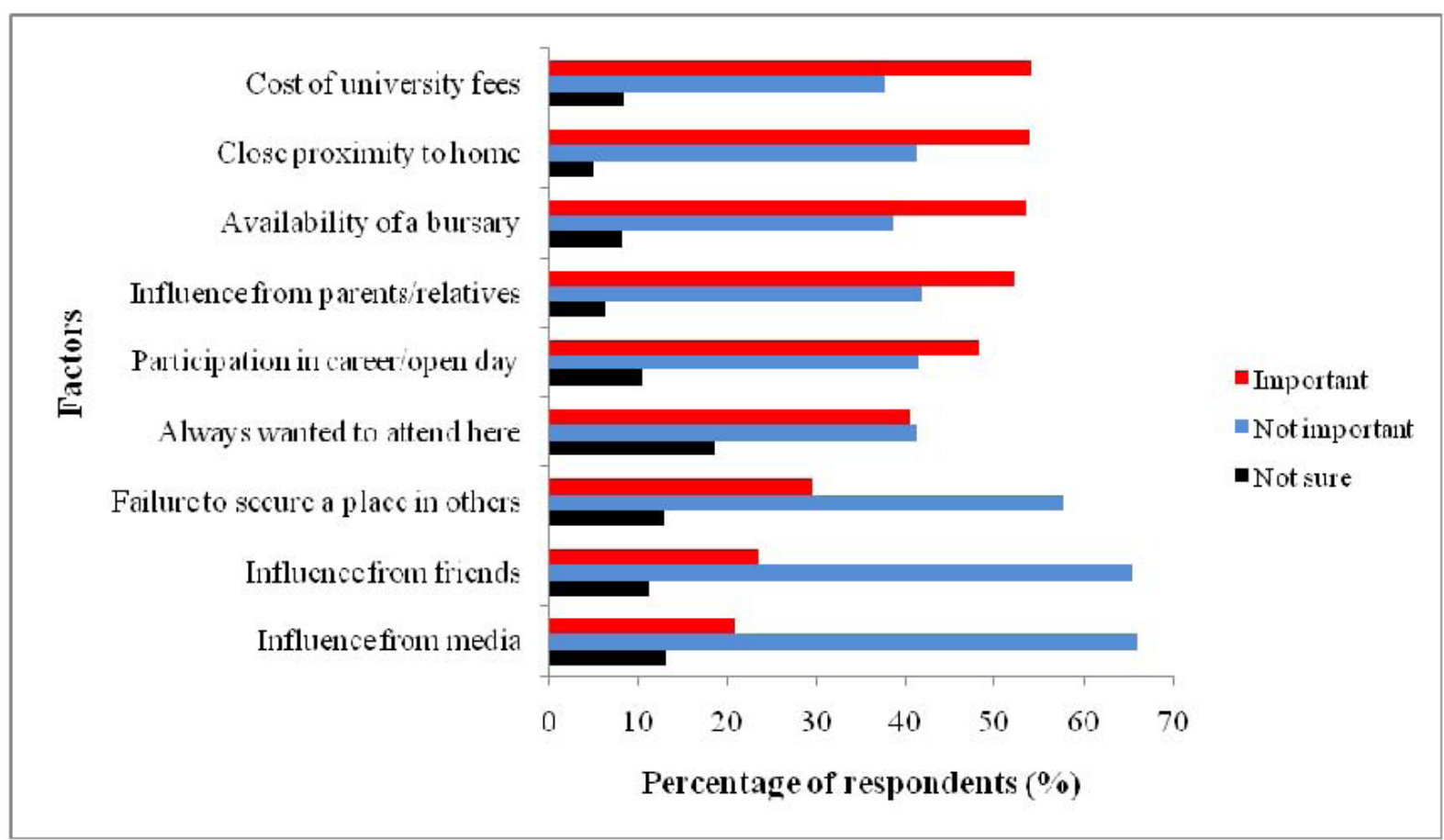

Figure 2: The ranking of importance of factors which influenced the decision of the respondents to choose their institution of learning. A few rated the influence from friends (23.5\%) and media (20.9\%) as important factors. 


\section{Discussion}

More females (69.5\%) than males (30.5\%) were pursuing optometry. This could be due to the females having more interest in the course or perhaps they had better entrance grades than the males, hence were given preference in the admission process. Racial imbalances were observed in the results with White students $(76.3 \%)$ and $(56.1 \%)$ respectively constituting the majority at the UFS and UJ. The majority $(96.6 \%)$ of those from the UL were Blacks, while at UKZN, the population included $43.5 \%$ Blacks and $40 \%$ Indians. These suggest that while historically white and black institutions have invested some efforts to diversify the racial composition of their students, optometry departments at these universities have not been able to fully effect a change in the student demographics. It is noteworthy that the proportion of Coloureds is low in all the institutions.

The highest proportions of students were from the provinces where institutions were located namely KwaZulu-Natal province (29.2\%), Gauteng (21.2\%), Free State (13.2\%) and Limpopo (11.1\%). Only a few respondents were from the North West province (2.1\%), Mpumalanga province (4.7\%), Eastern Cape province $(7.2 \%)$, Northern Cape $(2.6 \%)$ and Western Cape provinces $(5.7 \%)$. This may be attributed to the fact that these provinces have no universities that offer the optometry degree and presumably the course is not well-known in those provinces. This suggests the need for the institutions to proactively consider students from these provinces. Also, this suggests the need for awareness campaigns about optometry in these provinces. Such steps could assist in changing the demographics and distribution of optometrists in the country.

The majority of students were from the urban areas and this is of concern as many South Africans live in rural areas. Optometrists tend to prefer practicing in the urban areas, often leaving rural residents without optometric services ${ }^{18}$. Optometry institutions may need to look into strategies of improving admission of students from rural areas. Also, many South Africans living in rural areas may not be able to afford the cost of transportation to urban areas for eye care and possibly the higher costs of eye care there. If there are students from the rural areas, there is some chance that some of them might go back to the rural areas to practice, with the possibility of providing affordable eye care services and eliminating costs of transportation.

A significant number $(29.5 \%)$ of the respondents indicated that optometry was not their first choice, however, the majority wished to study courses such as medicine (53\%), pharmacy $(8 \%)$, dentistry $(8 \%)$, radiography $(5 \%)$ and physiotherapy $(5 \%)$. Courses of their first choice for others were occupational therapy, homeopathy, chiropractics and veterinary sciences $(6 \%)$. This aligned with the report that their motivation was to help other people, and this desire might still be met by studying and practising optometry. High rating of the desire to help others found in this study compares favourably with the study by Baboolal and Hutchinson ${ }^{19}$, in which first year medical students at the University of West Indies reported that helping others was a major factor influencing their choice of career. Many of the respondents (92\%) cited job availability as an important factor for choosing optometry as a profession. This may be related to the current unfavourable economic conditions and high unemployment rate in the country. This response is similar to that in a recent article in which $67 \%$ of Zimbabwean physiotherapy students cited job availability as a very important factor in choosing a career in physiotherapy ${ }^{7}$.

Success and happiness in a given career are often defined in terms of monetary wealth and recognition ${ }^{20}$. This view is reflected by responses in this study as $88.6 \%$ of the respondents indicated that the potential to earn a good income was a very important factor in their decision to choose optometry as a career. Also, the conditions of service are important factors in choosing a career. The majority $(83.7 \%)$ of respondents in this study indicated that flexible working hours, the ability to use their own initiative, status and prestige of the profession (71.1\%) were important factors in their choice of optometry. The perception on flexible hours and independence could have been influenced by the fact that most optometrists in South Africa are in private practice and therefore, do not work irregular hours including holidays unlike the nurses who work mainly in the public sector, and therefore have to work in shifts, including holidays. A similar finding was reported by Lambert et al ${ }^{11}$, who found that the majority of newly qualified doctors who chose ophthalmology as a career cited the pros- 
pect of good working hours and conditions as being important factors. Similarly, in a study by Noble ${ }^{12}$, ophthalmologists cited flexibility, mentorship and earning potential as important factors in their decision to pursue a career in ophthalmology.

While there may be minor differences in the admission requirements of the four optometry departments in South Africa, the entry requirements into the optometry degree are generally higher compared to some other degrees. Also, a good academic record with good marks in physical science and mathematics are required to enter optometry programmes. It is therefore not suprising that many respondents $(91.2 \%)$ rated subjects passed and points obtained in matriculation as very important factors in choosing optometry.

A large proportion of the respondents $(70.5 \%)$ rated treatment received from an optometrist as important in their decision of career choice. An inference of this could be that exposure to the profession through receiving treatment or working with an optometrist are important factors. This view is supported by the fact that almost two-thirds $(65.9 \%)$ rated the association with an optometrist as important. This finding is similar to those of Jones and Larke ${ }^{21}$, who found that past experience with professionals from the field of agriculture, seemed to increase students' interest in that career. Similarly, Ramsey et al ${ }^{22}$ and Soethout et $a^{23}$ reported that medical students were influenced to choose a career in medicine after participating in health care and clinical institutions. It is therefore, necessary for practicing optometrists to continue to offer quality services with good ethos. These will further enhance the image of the profession and attract students into optometry programmes.

Marketing is an important medium of promoting an organization and its activities. Perhaps the most common method of creating awareness of institutions and departments in South Africa is the career day, generally called Open Day, during which high school learners are invited to universities and information regarding the courses offered and career opportunities are given to them. Also, admission requirements and fee structures are explained to them. In this study, only $58.1 \%$ of the students reported that participation in open or career day was important in their career choice and this factor ranked 11th (second from the bottom ranked factor) in the order of importance. This raises questions about the effectiveness of marketing strategies such as career days that are undertaken by the universities for programmes such as optometry. Another common method of marketing institutions and programmes is via the media. Many of the respondents $(66.1 \%)$ rated influence of the media as "not important" in their choice of the institution of learning. Therefore, institutions offering optometry need to find additional innovative ways to raise awareness campaigns, particularly in rural areas and provinces where there are no universities that offer the degree. Noteworthy was the finding that neither parents nor relatives had a significant influence on career choice in optometry as only $56.3 \%$ rated this factor as important, ranking 12th (last) of the listed factors. This result contrasts with those of Ferry et $a l^{24}$ and Singaravelu et $a l^{25}$ who found that family and community were instrumental and influential in career choices among high school students in Pennsylvania. Counsellors and educators who work with high school students are therefore, advised to explore what role parents can play in their career choices and attempt to find ways of increasing positive support from parents. In addition, it may be important to explore the possible influence of teachers in the career decision-making process.

For some optometry students, specific reasons such as finances or proximity considerations may be a major factor for a particular institution. In the present study, just over a half (54.3\%) of the respondents rated the cost of university fees as an important factor in their decision to choose their institution of learning while a significant proportion $(37.5 \%)$ rated it as not important. Similarly, 54\% and 53.5\% respectively of the respondents rated close proximity to home and availability of a bursary as important, while $41.1 \%$ and $38.5 \%$ rated these factors as not important. Those who rated proximity and availability of bursary as not important probably have parents who could afford to pay the university fees or have loans and bursaries that cover the full costs of study. In South Africa, and perhaps in many developing countries of the world, a large proportion of those who live in the rural areas are relatively poorer ${ }^{18}$. It was therefore not suprising that the majority of respondents from rural areas rated finances $(84.6 \%)$ and proximity to home $(77 \%)$ as important in their choice of institution. Findings showed that knowledge of the institution of learning was not 
a significant influence on the choice of institution as $41.1 \%$ of the students rated "I have always wanted to attend this institution" as "not important".

In our opinion, institutions offering optometry in South Africa should consider the findings of this study and find innovative ways of using them to improve their strategies to attract prospective optometry students.

\section{Conclusion}

This study reveals the great influence of psychosocial motivation or personal factors (such as desire to help others, using one's own initiative, perceptions of the status and prestige of a career) in choosing optometry as a profession. Also, practical motivations such as job availability, subjects passed and points obtained in matric, the potential to earn a good salary and flexible work schedule were significant influences on career choice. On the other hand, the traditional methods of attracting prospective students such as the career or open day and media were not rated highly in this study. It is therefore, recommended that institutional marketing strategies should be extended to include other innovative strategies such as seminars where guidance counsellors and teachers become more interactive with students. Also, optometric practitioners may be invited to address students about the profession in order to create greater awareness. It is suggested that universities offering optometry degree should increase their awareness campaigns in high schools located in provinces where there are no universities that offer the optometry degree. This can be done through developing collaborative career awareness programmes and recruitment efforts between optometry departments and high schools located in such provinces.

\section{Acknowledgements}

The authors wish to acknowledge the following individuals who provided valuable research assistance: Mr N Naicker (UFS), Ms P von Poser (UJ), Mrs DT Sabela and Ms P Mathonsi (UKZN) and Mrs Thoko Chipi (UL).

\section{References}

1. Bandura A, Barbaranelli C, Caprara GV, Pastorelli C. Selfefficiency beliefs as shapers of children's aspirations and trajectories. Child Develop 200172 187-206.

2. Bryant BK, Zvonkovic AM, Reynolds P. Parenting in relation to children and adolescent vocational behaviours. $J$ Voc Behav 200669 149-175.

3. Hardigan PC, Cohen SR. Comparison of personality styles between students enrolled in osteopathic medicine, pharmacy, physical therapy, physician assistant and occupational therapy programmes. J Am Osteopath Assoc 199898 637641.

4. Nordhalm LA, Westbrook MT. Career development of female physiotherapists: stage four of a longitudinal survey. Aus J Physio 198531 10-16.

5. Ohman A, Stenlund H, Dahlgren L. Career choice, professional preferences and gender: the case of Swedish physiotherapy students. Adv Physio 20013 94-107.

6. Ohman A, Solomon P, Finch E. Career choice and professional preferences in a group of Canadian physiotherapy students. Adv Physio 20024 16-22.

7. Mkondo T, Mudzi W, Mbambo NP. Factors influencing Zimbabwean physiotherapy students in choosing physiotherapy as a career. S Afr J Physio 200763 26-31.

8. McCord JH, McDonald R, Sippel RS, Leverson G, Mahvi DM, Weber SM. Surgical career choices: the vital impact of mentoring. J Surg Res 20085 1-6.

9. Pinchot S, Barbara JB, Weber SM, Rikkers LF, Chen H. Are surgical progeny more likely to pursue a surgical career? $J$ Surg Res 2008147 253-259.

10. Willcockson IU, Phelps CL. Recruiting future neuroscientists: What asking the recruits can teach us. Neuro-Scientist 200410 594-597.

11. Lambert TW, Goldacre MJ, Bron AJ. Career choices for ophthalmology made by newly qualified doctors in the United Kingdom, 1974-2005. BMC Ophthalmol 20088 14711478.

12. Noble J. Factors influencing career choice in ophthalmology. Can J Ophthalmol 200641 596-599.

13. Gedde, S., Buddenz D, Haft P, Tielsch J, Lee Y, Quieley H. Factors influencing career choices among graduating ophthalmology residents. Ophthalmol 2005112 1247-1254.

14. Mbambo NP. Factors influencing black students in choosing physiotherapy as a career. Unpublished research, 2002, University of the Witwatersrand, South Africa.

15. Mimura C. What motivates people to enter professional nursing? Int J Nurs Studies 20087 1-3.

16. Lai HL, Lin YP, Chang HK, Chen CJ, Peng TC, Chang FM. Is nursing profession my first choice? A follow up survey in pre-registration student nurses. Nurs Educ Today 200828 768-776.

17. Health Professions Council of South Africa (HPCSA). Minutes of the Executive Committee Meeting with Heads of Optometry Departments held at Emperors Palace, Kempton Park, 05 December 2008. 
18. Oduntan AO, Louw A, Moodley VR, Richter M, Von Poser P. Perceptions, expectations, apprehensions and realities of graduating South African optometry students. S Afr Optom 200766 94-108.

19. Baboolal NS, Hutchinson GA. Factors affecting future choice of speciality among first-year of the University of West Indies, Trinidad. J Med Educ 200741 50-56.

20. Cutler JL, Alspector SL, Harding KJ, Wright LL, Graham MJ. Medical students' perceptions of psychiatry as a career choice. Acad Psych 200630 144-149.

21. Jones WA, Larke A. Enhancing the life for Hispanic individuals through career preparation. J Hisp Higher Educ 2005 4 5-18.
22. Ramsey AH, Haq C, Gjerde CL, Rothenberg D. Career influence of an international health experience during medical school. Fam Med 200436 412-416.

23. Soethout MBM, ten Cate TJ, van der Wal G. Factors associated with the nature and timing and stability of the specialty career choices of recently graduated doctors in European countries. Med Educ 2004 9 7-16.

24. Ferry TR, Fouad NA, Smith PL. The role of family context in a social cognitive model for career-related choice behaviour: A math and science perspective. J Voc Behav 200057 348-364.

25. Singaravelu HD, White LJ, Bringaze TB. Factors influencing international students career choice. J Career Develop 200532 45-49.

\section{Appendix 1}

Dear Student,

This survey is being conducted to establish the factors that influence Optometry students studying in South Africa in choosing their career and institution of learning. Please circle the option that best describes your response. Please do not indicate your name anywhere in the questionnaire.

\begin{tabular}{|l|}
\hline 1. Age: $. \ldots \ldots \ldots \ldots \ldots \ldots \ldots . . .(y e a r s)$ \\
\hline 2. Gender: Male [1] Female [2] \\
\hline 3. Race: Black [1] Coloured [2] Indian [3] White [4] Other [5] (please specify)
\end{tabular}

4. Please select: South African student [1] Intemational [2]

5. For South African students, please indicate y our province of origin: Eastern Cape [1] Free State [2] Gauteng [3]

KwaZulu-Natal [4] Limpopo [5] Mpumalanga [6] Northern Cape [7] North West [8] Western Cape [9]

6.1 If you are international student, please indicate country of origin....

7. Your home area is in a: Urban [1] Rural [2] Other (please specify) [3]

8. Please indicate your current the institution: UFS [1] UJ [2] UKZN [3] UL [4]

9. Please indicate your current year of study: First year [1] Second year [2] Third year [3] Fourth year [4]

10. Was this institution y our first choice? Yes [1] No [2]

11. If your answer to question 11 is No, which institution was y our first choice?

12. Was Optometry y our first choice? Yes [1] No [2]

13. If Optometry was not your first choice, please indicate which degree/course was your first choice.

14. Please rate the importance of the following factors in your decision to choose Optometry as a career. PLEASE, LET

YOUR ANSWER BE what it was when you were choosing the course, NOT how you feel now!! 
14.1 Participation in career day or open day: Important [1] Not important [2] Not sure [3]

14.2 Subjects passed and points obtained in matric: Important [1] Not important [2] Not sure [3]

14.3 Job availability after graduation: Important [1] Not important [2] Not sure [3]

14.4 Desire to help other people: Important [1] Not important [2] Not sure [3]

14.5 Failure to secure a place in other degree/s: Important [1] Not important [2] Not sure [3]

14.7 Potential to earn a good salary: Important [1] Not important [2] Not sure [3]

14.8 Flexible work schedule: Important [1] Not important [2] Not sure [3]

14.9 Professional status and prestige of the profession: Important [1] Not important [2] Not sure [3]

14.10 Opportunity to interact with other professionals: Important [1] Not important [2] Not sure [3]

14.11 Opportunity to use my own initiative: Important [1] Not important [2] Not sure [3]

14.12 I always wanted to be an optometrist: Important [1] Not important [2] Not sure [3]

14.13 Past experience, working with an optometrist: Important [1] Not important [2] Not sure [3]

14.14 Treatment received from an optometrist: Important [1] Not important [2] Not sure [3]

14.15 Influence from parents or relatives: Important [1] Not important [2] Not sure [3]

14.16 Influence from friends: Important [1] Not important [2] Not sure [3]

15. Please rate the importance of the following factors in your decision to choose the institution you are studying at:

15.1 I always wanted to attend this institution: Important [1] Not important [2] Not sure [3]

15.2 Close proximity to home: Important [1] Not important [2] Not sure [3]

15.3 Influence from parents or relatives: Important [1] Not important [2] Not sure [3]

15.4 Media influence: Important [1] Not important [2] Not sure [3]

15.5 Failure to secure a place in other universities: Important [1] Not important [2] Not sure [3]

15.6 Cost of the university fees: Important [1] Not important [2] Not sure [3]

15.7 Availability of a bursary: Important [1] Not important [2] Not sure [3]

15.8 Participation in career day/open day: Important [1] Not important [2] Not sure [3]

15.9 Influence from mass media: Important [1] Not important [2] Not sure [3]

15.10 Influence from friends: Important [1] Not important [2] Not sure [3]

Thank you for taking time to complete this questionnaire. 